\title{
AVISOS, ANUNCIOS, RECLAMOS Y PUBLICIDAD EN ESPAÑA. SIGLOS XVIII Y XIX
}

\author{
$\mathrm{M}^{\mathrm{a}}$ Dolores Fernández Poyatos \\ (Universidad de Alicante) \\ dolores.fernandez@ua.es \\ Emilio Feliu García \\ (Universidad de Alicante) \\ Emilio.feliu@ua.es
}

\begin{abstract}
Resumen: Este artículo analiza diversas manifestaciones publicitarias aparecidas en la prensa española de los siglos XVIII y XIX. Considerando que la publicidad moderna nace en los países primero industrializados en torno a esas fechas, esta investigación se ha planteado la hipótesis de que en España, aun con retraso, se inició un proceso similar. Para la recopilación y selección de hechos, hemos utilizado las colecciones digitalizadas de portales que recientemente ofrecen el acceso libre a sus fondos; en particular, los de la Biblioteca Nacional de España, el Archivo de Revistas Catalanas Antiguas y la Hemeroteca Municipal de Madrid.
\end{abstract}

Palabras claves: Aviso, anuncio, reclamo, prensa, publicidad

Abstract: This article analyses several public advertising manifestations published in the Spanish press during the 18th \& 19th centuries. Considering that the modern advertising is born in the first industrialized countries at that time, this investigation has presented the next hypothesis: In Spain, still with delay, a similar process was initiated. In order to compile and select the facts, we have used the digitalized collections of different sites that recently offer free access to its contents; in particular, the ones allocated in the Spanish National Library, the old Catalonian magazines and the Newspaper Library of Madrid.

Key Words: Notice, advertisement, lure, press, advertising.

\section{INTRODUCCIÓN}

Al abordar un tema como el de la publicidad de hace más de doscientos años, una cuestión parece imponerse: ¿a qué forma de comunicación se puede llamar publicidad en un sentido moderno? El presente trabajo asume que desde mediados del siglo XVIII existió una embrionaria actividad anunciadora, que rebasaba el ámbito de lo público para entenderse como comercial con un significado muy amplio y genérico.

La investigación sobre el periodismo en España ha señalado esta cuestión, que la investigación publicitaria ha mantenido sin ahondar en esa parcela de la gestación de la actividad anunciadora que precede al primer tercio del siglo XX, 
cuando la Historia en todos los órdenes reconoce la modernidad española. A pesar de que lo anterior al siglo XX no es stricto sensu publicidad, sí es posible considerar diversas manifestaciones - avisos, anuncios, reclamos- como antecedentes de la publicidad del siglo XX.

Así lo señaló Nieto (1984: 47-56), cuyo trabajo sobre la Gaceta de Madrid durante los siglos XVIII y XIX estima el nacimiento de la publicidad comercial junto al de la prensa periódica hacia mediados del siglo XVIII. Rueda y Barbero (2000: 109-123), también interesados por esta cuestión, analizan la comunicación comercial de diversas instituciones financieras madrileñas a mediados del siglo XIX, destacando la multiplicidad y abundancia de formas publicitarias en la prensa decimonónica hasta la crisis de 1866. En ambos estudios se reconoce la configuración de la publicidad como ingreso cualificado para las publicaciones periódicas.

$\mathrm{Si}$ atendemos a estos términos desde las entradas que registran los diccionarios de la Real Academia Española de la Lengua (RAE a partir de ahora), la voz aviso se recoge por primera vez en 1726 como "Notícia dada á otro de lo que sucéde, ó acontece, ó le conviene para algun fin" (RAE, 1726: 503), asimilándose a anuncio en 1970, curiosamente como un americanismo (RAE, 1970: 1378).

En el mismo diccionario de 1726, está anuncio con el significado de "Notícia, ó nueva que se dá, ó publica" (RAE, 1726: 314), y también como presagio. Con un sentido comercial, lo encontramos en 1822: "Noticia que se da por escrito de la venta de alguna obra literaria ó de cualquier otra cosa que se quiere hacer saber" (RAE, 1822: 867); acepción que continúa hasta 1852, para desaparecer en el diccionario de 1869, cuando es sustituida de nuevo por la que tenía en 1726 . En 1899, se introduce "Conjunto de palabras ó signos por medio de los cuales se anuncia algo" (RAE, 1899: 733), que cambia en el diccionario histórico de 1933 por el de "Escrito en que se anuncia algo", aunque su origen se remonta al Opúsculo de la gramática satírica (1828) de Puigblanch: "Insertó su anuncio y elogio en su Catálogo" (RAE, 1933: 624).

La voz reclamo aparece en 1737 con variadas acepciones -instrumento para llamar aves, reclamación, cualquier cosa que atrae, llama o convida, etc. (RAE, 1737: 518) - , que se mantienen hasta el diccionario de 1970, cuando se añade el de "Propaganda de una mercancía, espectáculo, doctrina, etc." (RAE, 1970: 1414).

Por último, el término publicidad también se fecha en 1737 como "Estado ó calidad de las cosas públicas" (RAE, 1737: 420), entre otros significados. Ya en 1925 adquiere cierto cariz comercial: "Conjunto de medios que se emplean para divulgar o extender la noticia de las cosas o de los hechos" (RAE, 1925: 998), hasta 1970, cuando se extiende a "Divulgación de noticias o anuncios de carácter comercial para atraer a posibles compradores, espectadores, usuarios, etc." (RAE, 1970: 1413).

Frente a la tardía entrada de estos vocablos en los diccionarios de la RAE con el significado moderno que habría de imponerse, se confirma su presencia en documentos bastante anteriores. Así, aviso es utilizado por Nipho (1-2-1758: 
23) en el Diario Noticioso, Curioso-Erudito, Comercial, Público y Económico con el significado de noticia, pero también con otro más actual a través de la forma Esquela de aviso: "cedulas, ò esquelas de aviso se han de llevar al DIARIO".

La voz reclamo, cuyo proceso de aplicación con significación comercial en el diccionario se alarga más de doscientos años, aparece ya en 1842 en el periódico El Gratis, cuyos editores la adoptan como préstamo (del francés reclame), al no encontrar un término equivalente en castellano:

[...] si el reclamo, usado en su verdadera acepción, llama las vandadas de pájaros y las acerca al cazador, en el sentido que nosotros le damos tambien atraerá un enjambre de compradores á los que le usen. [...] Los reclamos son unos pequeños artículos de elogio que colocan en el fondo del periódico, entre los artículos de redaccion, como si en efecto lo fuesen, no siendo otro el autor que la parte interesada. Los reclamos se insertan ordinariamente apoyando un anuncio publicado (1-8-1842: 2).

Reclamo como neologismo en cuanto a su significado; se trata de una neología de sentido, pues se emplea un significante ya existente en español, al que se le otorga un contenido que antes no tenía (Dubois, 1998: 440-441). El uso de esta voz en el argot publicitario llega hasta nuestros días, siendo muy frecuente como tecnicismo publicitario en el primer tercio del siglo XX.

Algo parecido sucede con publicidad, que sólo amplía su definición de cosa pública en 1925; sin embargo, existen diarios en los que ya se verifica otro uso en 1842; en particular, en El Gratis el 1 de agosto, a propósito del elogio a la publicidad que realizan sus editores.

La presencia de estos términos en documentos tan relativamente tempranos sirve para calificar como tardía su incorporación a los diccionarios (repertorios sancionados por el uso de la colectividad), pero también para constatar su utilización con un sentido más amplio por una actividad comunicativa que no habría de consolidarse hasta años después.

\section{METODOLOGÍA}

Esta investigación sobre los inicios de la actividad publicitaria ha seguido las pautas de la llamada por los epistemólogos lógica de la abducción, que conjuga el método hipotético deductivo y el inductivo, de manera que el estudio y el contacto con las fuentes históricas lleva a descubrir hechos que pueden modificar las hipótesis iniciales. Estos hallazgos no son, por lo tanto, lógicos, sino empíricos e inductivos, aunque inmediatamente se vuelva a la teoría para explicarlos.

Dada la importancia que las primeras formas publicitarias han tenido en la evolución de la prensa y de la misma publicidad, y debido a la escasez de investigaciones al respecto en España, nuestro objetivo se ha centrado en verificar su presencia durante los siglos XVIII y XIX. La constatación de su aparición y ordenación en otros países nos anima a plantear la hipótesis de que también en España la publicidad hubo de seguir un proceso similar que la llevó a adquirir 
318 Avisos, anuncios, reclamos y publicidad en España. Siglos XVIII y XIX

su sentido moderno.

Para la recopilación y selección de hechos se han utilizado tres clases de fuentes: bibliografía de la época, bibliografía contemporánea y fuentes hemerográficas. Estas últimas han sido analizadas a través de las colecciones digitalizadas de portales con acceso libre a sus fondos (Malalana, 2004; Checa, 2008); concretamente, los de la Biblioteca Nacional de España (BNE), el Archivo de Revistas Catalanas Antiguas (ARCA) y la Hemeroteca municipal de Madrid (HMM). Con ellas, se ha esbozado la evolución de los anuncios desde 1758 hasta finales del siglo XIX. La fecha de inicio coincide con la aparición de la primera tipología de anuncios; el final del siglo, con el arraigo de la prensa informativa, que ya considera necesarias las inserciones publicitarias para su financiación y permanencia.

La muestra de estudio es resultado de una selección que obedece, primero, a un criterio cronológico: 1) Publicaciones periódicas del siglo XVIII y 2) Publicaciones periódicas del siglo XIX. En el primer grupo se obtuvieron 26 publicaciones y en el segundo 889. A continuación, se optó por revisar diez ejemplares de todas las cabeceras del siglo XVIII (siempre el número 1 y el último de cada publicación; el resto se decidió de forma aleatoria); en total se analizaron 260 ejemplares.

Respecto a los periódicos del siglo XIX, se decidió realizar un estudio exploratorio por diversas razones: las impresionantes cifras obtenidas (889 cabeceras) y el mismo objetivo de la investigación (verificar la presencia de manifestaciones publicitarias). Gracias a las ventajas de las nuevas tecnologías para la consulta documental, se efectuó una explotación intensiva de fuentes que consistió en revisar tres ejemplares (siempre el primer número y dos al azar) de 93 cabeceras, esto es, 279 ejemplares. El criterio de selección fue doble; por una parte, se consultó prensa de la denominada por la historiografía "de empresa" (Seoane, 1992: 291); por otra, se realizó un análisis de cabeceras elegidas aleatoriamente, así como de otras que contuvieran voces representativas de la actividad comercial y anunciadora de la época: aviso, anuncio, diario, mercurio, semanario, gaceta, correo, boletín, industria, mercantil, comercio. Este procedimiento dio como resultado el relevante hallazgo de El Gratis - primer diario gratuito de anuncios-. A la vista de este caso y de otros inéditos, se decidió un posterior estudio de mayor profundidad sobre la actividad publicitaria en la prensa decimonónica.

\section{PRIMEROS AVISOS COMERCIALES EN LA PRENSA ESPAÑOLA. SIGLO XVIII}

Los investigadores han destacado, sobre todo en Madrid y Barcelona, la aparición de diarios con anuncios diversos; en la primera, el Diario Noticioso, Curioso-Erudito, Comercial, Público y Económico, fundado en 1758 por Francisco Manuel Mariano Nipho y Cajigal; en la segunda, el Diario Curioso, Histórico, Erudito, Comercial Público y Económico (1762) de Pedro Ángel de Tarazona.

Al de Nipho se le considera el primer diario orientado a la divulgación cultural y a la información económica y comercial; labor que cumplió "a partir de una 
relación de anuncios de ventas, alquileres, ofertas y demandas, y realizar una labor de 'divulgación' a través de sus artículos editoriales" (Sáiz , 1990: 123); lo que llevó a Altabella a considerar a Nipho "fundador del primer diario español y creador de la publicidad periodística en España" (1964: 61). La inserción de estos avisos, así como las notas que enviaban los lectores al periódico, eran gratuitas y "constituyen el precedente de las futuras secciones de publicidad y de correspondencia" (Sáiz, 1990: 125). Precisamente, el sentido de la periodicidad diaria del Diario Noticioso se explica por la inserción de los avisos, tal y como el propio Nipho indicó en el plan del diario contenido en el primer número, donde además advierte por qué desestimó consejos de "Muchos sujetos [que le] aconsejaron diera los avisos [...] de ocho à ocho dias, ò quando mas dos veces à la semana" (1-2-1758: 22).

Primer número, además, que incluye la primera tipología de anuncios conocida; en el artículo segundo, explicaba Nipho las razones de tal categorización: "se darà noticia de cuanto ocurra importante, y necesario al Comercio Civil, y Economico para alivio de todos" (1-2-1758: 11-12); ordenando, a continuación, los avisos en diez puntos: 1) Ventas de casas, ropas, muebles, coches...; 2) Almonedas de muebles, ropas y el menaje de una casa; 3) Géneros de toda especie: paños, lienzos, libros; 4) Frutos, abastos, licores y géneros similares; 5) Avisos de robos y pérdidas, así como de hechos luctuosos y accidentes; 6) Avisos de invenciones curiosas de artistas liberales y mecánicos, de espectáculos, de sujetos con habilidades útiles como cirujanos, dentistas, maestros de danza, esgrima...; 7) Señoras, amos o amas que necesiten servicio doméstico; 8) Criados que se hallen sin acomodo, así como costureras y aplanchadoras; también se dirigía a mujeres que enseñaban a las niñas labores domésticas; 9) Amas de criar niños y 10) Préstamos y cobranzas.

De la lectura de los diez puntos, y las reflexiones que los acompañan, se concluyen ciertas ventajas que Nipho explicó al idear esta novedosa sección de avisos: 1) Acelerar la demanda de productos, 2) Activar el comercio, 3) Aumentar el alcance y la superioridad del anuncio en prensa como medio frente al cartel, que era el más usual y conocido de la época y 4) Combatir la obsolescencia de los productos. Funciones que, en su mayoría al menos, se atribuyen en la actualidad a la acción publicitaria. Conceptos, de otra parte, que anticipan las teorías de Galbraith (1968) y Baudrillard (1974) acerca de la demanda inducida de los productos a través de aceleradores artificiales, entre los que la publicidad cumple una función esencial.

Es interesante considerar estas actividades de producción y servicios y compararlas con las actuales de índole publicitaria como la de Infoadex. De los veintidós sectores de que consta esta base de datos, encontramos representados Alimentación, Automoción, Bebidas, Construcción, Cultura, Enseñanza y Medios de comunicación, Deportes y Tiempo libre, Hogar, Objetos personales, Servicios públicos y privados, Textil y Vestimenta y Varios. Si bien las categorías y productos que los integran son a veces heterogéneos y, por lo tanto, los límites entre 
sectores son difusos, tal clasificación retrata claramente la economía y sociedad de mediados del siglo XVIII, reflejando productos y actividades dominantes o emergentes. Estos avisos aparecieron siempre en las dos últimas páginas del diario bajo el epígrafe "Noticias de comercio".

La primera época del diario acabó el 31 de diciembre de 1781; en ella, se observa un paulatino incremento de avisos, de manera que muchas ediciones llegaron a tener dos planas completas. Así mismo, comienzan a publicarse avisos que transcienden la función informativa que los caracterizaba; uno especialmente interesante se encuentra en la cuarta página del diario del 27 de diciembre de 1781: "Los que conocen las virtudes del Elixir odontálgico saben que es un excelente remedio contra las fluxiones, dolores de muelas y dientes, [...] también para la conservación de las encías, y que con la suavidad de su olor corrige y hace agradable el aliento; [...] los vende Mr. Duclos de la Mote. Lo dà à los pobres gratis".

Se aprecia la intención persuasiva en el uso de la adjetivación, que lo aleja del resto de avisos del momento; se trata de un específico, cuya publicidad fue vital para el desarrollo de la prensa y de la misma publicidad (Checa, 2007: 81). Entre finales del siglo XIX y el primer tercio del siglo XX, en España, la publicidad de específicos fue con mucho la más abundante y vital (Fernández Poyatos, 2011: 117).

Desde julio de 1786 hasta diciembre de 1787, tuvo por título Diario curioso, erudito, económico y comercial. En el primer número (1-7-1786), se explica la estructura del diario, en la que permanece la sección de avisos con la misma clasificación. Entre 1788 y 1825, cambió su título por Diario de Madrid y desde octubre de 1825 hasta 1847, por Diario de avisos de Madrid. En enero de 1847 inicia una nueva etapa que llega hasta 1917 como Diario oficial de avisos de Madrid. Durante esos años, y bajo la leyenda "Noticias particulares de Madrid", continuaron las noticias sobre ventas, alquileres, pérdidas, servicio doméstico, bibliografía, fiestas, etc. Sección que para Rueda y Barbero (2000: 115) sería reflejo de la pluralidad del mercado madrileño en el siglo XIX, así como un indicador privilegiado para advertir sus características.

Otros periódicos de Madrid también incluían avisos, aunque más eventualmente. El Correo de los ciegos (1786-1791) publicaba, como el de Nipho, avisos sobre libros, servicio doméstico, etc. Algunos periódicos mensuales y quincenales como El Mercurio de España (1784-1830) contenían escasos y sencillos avisos, de estilo neutro e informativo. El Correo mercantil de España y sus Indias (17921808), de frecuencia quincenal, potenciaba "noticias y artículos destinados a los agentes productivos de la sociedad", incluyendo abundante información comercial, pero escasos anuncios que, en general, hacían referencia a obras literarias o científicas, con una redacción carente de énfasis.

En otras ciudades de España, también se editaron periódicos de parecida factura. El Diario Pinciano de Valladolid (1787-1788) tenía una sección en las 
últimas páginas con la rúbrica "Noticias particulares", donde aparecen ocasionalmente avisos similares: pérdidas, nombramientos, venta de inmuebles, etc. De igual forma, el Semanario de Salamanca (1793-1798) reservaba las dos últimas planas para robos, pérdidas, ventas, libros, arrendamientos; e, igualmente, el Diario de Valencia (1790-1834) contenía una sección fija al final para avisos de limpieza, sirvientes, ventas, alquileres, hallazgos, etc.

En Barcelona, destacan a finales del siglo XVIII dos diarios: el Diario Curioso, Histórico, Erudito y Comercial, Público y Económico y el Diario de Barcelona. El primero fue editado en 1762 por Pedro Ángel de Tarazona; en el privilegio de impresión, se explica cómo se le otorga licencia para escribir, imprimir, publicar y vender en Barcelona un diario igual "al que se imprimía con arreglo en todo al concedido al citado Don Manuel Ruiz de Uribe" (12-1761: 5). No es casualidad que el plan del diario fuera casi idéntico al de Nipho: el artículo segundo -Comercial, y Económico- se organizó en once puntos, diferenciándose del diario de Nipho en la inclusión de un punto nuevo -el séptimo- para arrendamientos de diezmos, baronías, heredades. Sin embargo, y a pesar de la importancia comercial de Barcelona, apenas llegó a editarse un mes.

Volvió a aparecer el 1 de junio de 1772 como Diario Evangélico, Histórico-Político. En el primer número, Tarazona expuso la organización del periódico, del que reservaba las dos últimas páginas "para las noticias Comerciables, y Economicas Ocurrentes". En esta sección, se informaba del movimiento del puerto barcelonés y se daba noticia de asuntos que se recogían bajo el lema de "Noticias familiares", de carácter análogo a las "Noticas de Madrid" de Nipho: alquileres, ofertas de servidumbre, pérdidas, etc. bajo la forma habitual de la redacción periodística. Volvió a cambiar la cabecera el 13 de junio de 1772 por la que tuvo en su origen -Diario Curioso, Histórico, Erudito, Comercial, Civil y Económico-, manteniendo hasta el final (31-01-1773) la estructura referida.

El Diario de Barcelona fue fundado en 1792 por Pedro Pablo Usson. La lectura del privilegio de impresión otorgado por Carlos IV el 6 de abril de 1792 justifica las razones de su publicación:

Por cuanto por D. Pedro Pablo Usson se me hizo presente ser útil el establecimiento de un Diario en la Ciudad de Barcelona, a imitación del de Valencia y de la mi Corte, tanto por su comercio como por el gran consumo de sus fábricas y demás tráfico, $[\ldots]$ insertándose como quiero se inserten en dicho Diario las noticias públicas y avisos de navíos y sus cargas y demás conducentes al comercio e industria, [...] por lo mucho que puede contribuir al fomento del comercio y fábricas de dicha ciudad de Barcelona facilitando la salida de las manufacturas del país ${ }^{1}$.

A mediados del siglo XIX, el Diario de Barcelona pasó de "simple gaceta informativa de avisos y anuncios de interés local [a consolidarse como] un órgano 
de opinión influyente y prestigioso" (Seoane, 1992: 313-314). Y, al igual que los de Nipho y Tarazona, insertaba avisos de toda índole, entre los que destaca el que apareció en el primer número bajo el título de Noticia y que ponderaba unas "pastillas que no eran otra cosa que los actuales cubitos de caldo concentrado" (Aubeyzón, ¿1928?: 29). Se estructuraba también en dos partes. La primera, relativa a temas diversos - historia, medicina, astronomía...-; la segunda, llamada "Noticias particulares de Barcelona", publicaba información sobre el tránsito en los puertos y avisos de índole variada: libros, alquileres, pérdidas, ventas diversas, etc. Meses después de su aparición, este segundo bloque llegó a desplazar el primero, probablemente por la buena acogida que tuvo entre el público barcelonés (Guillamet, 2001: 6).

\section{PRENSA Y PUBLICIDAD EN EL SIGLO XIX}

\subsection{Diarios de gran tirada}

Para los estudiosos de la prensa, el siglo XIX es por excelencia el siglo del periodismo como vehículo de opinión, de cruzada política y de cultura, ante todo, y de aviso e información comercial, después (Seoane, 1992: 313-314). Sin embargo, concurren importantes rémoras en su desarrollo. Por una parte, la corta vida de las cabeceras; por otra, la pequeñez de las tiradas; reflejo ambas de los críticos acontecimientos económicos y políticos vividos en España y víctima, la segunda, de la pertinaz censura. La excesiva sujeción a las vicisitudes e ideologías políticas al uso fue la causa principal de la fugacidad y precariedad de las cabeceras.

Entre 1858 y 1909, destaca el incremento del número de periódicos. En Madrid, Brotel habla de crecimiento absoluto en el caso de los científicos y literarios y los de carácter político, siendo el desarrollo del primer grupo mucho mayor que el del segundo (1975: 28). Entre los factores que considera, subraya el aspecto legal. La ley del 7 de enero de 1879 suprimió la exigencia de un depósito previo para crear diarios y periódicos, que marcó el primer signo de reactivación en la prensa, produciéndose la liberalización definitiva con la Ley de Imprenta de 1883. Esta evolución no fue muy distinta a lo ocurrido en otros países: "la eliminación en una batalla más económica que ideológica [...] se ve perfectamente en la desaparición de los periódicos políticos no diarios, que no pueden competir con los 'grandes' diarios, [...] sobre todo, por sus medios económicos" (Brotel, 1975: 31).

La salvedad a la incierta vida de las cabeceras estuvo representada por la aparición del periódico "noticiero, informativo, que se pretende neutral o al menos independiente en política, del que es prototipo La Correspondencia de España" (Seoane, 1992: 16), y en el que la publicidad tuvo un papel esencial. Existió antes una embrionaria prensa comercial más allá de los avisos referidos en el

\footnotetext{
${ }^{1}$ Sáiz, op. cit., pp. 231-232, lo toma de Molist Pol, E. (1974): El Diario de Barcelona, 1792-1963. Su historia, sus hombres y su proyección pública. Madrid: Editora Nacional, p. 13.
} 
epígrafe anterior: la Carta Autógrafa editada en 1848 por Manuel de Santa Ana y Las Novedades, fundado en 1850 por Ángel Fernández de los Ríos, iniciador del periodismo de información barata y popular (Seoane, 1992: 200-201). La Carta Autógrafa fue pronto transformada por Santa Ana en La Correspondencia de España (1859), viniendo a convertirse en "el primer periódico que disfrutó de una contratación publicitaria continua" (Pérez Ruiz, 2001: 26) y reservando la cuarta plana para "unas gacetillas, [...], que eran una bendición de Dios, pues allí iban cultos, modas, chascarrillos y anuncios en el más disparejo revoltijo" (Gutiérrez, 1925: 502-503).

Progresivamente, los anuncios fueron llenando la cuarta plana e invadiendo la tercera. El 10 de mayo de 1870, La llustración Española y Americana afirmaba que La Correspondencia, "además de ser un gran elemento de propaganda, sostiene á numerosas familias. [...] produce además cada año á su propietario de 30.000 á 35.000 duros; 18 ó 20.000 producen solo los anuncios". En 1872, "imprimía 17.520.000 ejemplares al año, ofreciendo un movimiento de fondos de más de cuatro millones anuales. En 1871 sus anuncios han alcanzado la respetable cifra de 500.000 reales" (30-4-1872).

Testimonios apreciables por dos aspectos. Primero, por la magnitud de la cifra en términos absolutos, y segundo, porque del total de los ingresos -unos 30.000 reales-, más de la mitad (el $57,14 \%$ ) corresponde a los obtenidos por publicidad. De lo que resultaría que el diario de Santa Ana se estaba comportando en el aspecto crematístico como un diario moderno que gracias a su espectacular tirada atraía a numerosos anunciantes. Santa Ana fue un ejemplo excepcional de "capacidad de succión tecnológica con la producción masiva de impresos o con una diversificación empresarial que [concibió el] negocio editorial y periodístico como matriz para una acumulación original de capital" (Rueda, 1999: 352).

A partir de la década de 1870, encontrar anuncios en los periódicos se volvió un hecho bastante habitual, consolidándose la cuarta plana como espacio acostumbrado de inserción. Si bien La Correspondencia fue el iniciador de un nuevo modelo de prensa que el tiempo habría de afianzar, esto es, el cambio del periodismo de opinión al periodismo de información facilitado por la modalidad de venta callejera y por los ingresos percibidos por la publicidad, hubo otros como El Imparcial y El Liberal que, junto a aquél, formaron la tríada que fijó esta evolución.

Fundado en 1867, El Imparcial fue el encargado de consolidar el periodismo iniciado por Santa Ana con La Correspondencia de España. Desde entonces, "los periódicos que marcharán siempre en cabeza de tirada serán los de este tipo, más atentos a servir los intereses de la Empresa que los de un partido, para lo cual han de conseguir muchos anunciantes y muchos lectores, siempre en estrechísima conexión" (Seoane, 1992: 16-17). Entendemos que servir los intereses de la Empresa y conseguir muchos anunciantes es comportarse como soporte publicitario, y no sólo como medio de comunicación.

El Liberal nació el 31 de mayo de 1879, fruto de la disensión de un grupo de 


\section{Avisos, anuncios, reclamos y publicidad en España. Siglos XVIII y XIX}

redactores de El Imparcial, descontentos con la línea restauradora de su director. Su importancia para la publicidad radica en la publicación el 2 de octubre de 1879 de una convulsiva encuesta, donde daba razón de las diferencias habidas entre el número de ejemplares que los periódicos decían tirar y los que efectivamente tiraban. Las divergencias entre un dato y otro provenían del modo de calcular y acreditar, oficial y públicamente, el tiraje. Respecto del cálculo, el número de la tirada equivalía al pago del impuesto por timbre que los periódicos habían realizado. La Gaceta de Madrid publicaba mensualmente la recaudación obtenida por el timbre que los periódicos satisfacían por su envío a provincias. La cuota del timbre fue unificada por un Real Decreto en mayo de 1871; su importancia era vital por ser "la única fuente disponible para satisfacer sistemáticamente el número de ejemplares que se dedicaban a suscriptores y lectores de provincias" (Castillo, 1975: 151). La lectura es obvia: cuanto mayor era el pago, mayor era la tirada; dicho de otra forma, pagar más timbre significaba, teóricamente, mayor número de ejemplares en circulación y, por lo tanto, mayor número de lectores y esto, nadie lo duda, interesaba $-\mathrm{y}$ mucho- a los anunciantes.

No dudamos de que a El Liberal le guiaron preocupaciones éticas como la veracidad de las tiradas, pero desde luego también fueron inquietudes crematísticas derivadas de su reciente constitución como empresa periodística. Digamos que la publicación de dicha encuesta fue una acertada y oportuna táctica comercial para una cabecera que se estrenaba en un mercado dominado por La Correspondencia de España y El Imparcial, y donde la publicidad aportaba unos ingresos vitales.

Los periódicos madrileños publicaron entre 1881 y 1887 comunicados exigiendo nuevas medidas de control para verificar las tiradas. También los anunciantes, a quienes interesaba este asunto, se implicaron en esta reivindicación. Es el caso del Comunicado: Carta de un anunciante, aparecido el 21 de enero de 1882 en El Liberal, que explica con lúcida contundencia la causa subyacente a estas disputas y que contiene afirmaciones de sorprendente vigencia en el ámbito publicitario:

Del anuncio viven los diarios de gran circulación [...]; el suscritor no se hará la ilusion de que por cinco céntimos tan sólo puede tener todo lo que supone y cuesta un diario como El Liberal, El Imparcial ó La Correspondencia. La cuestion del anuncio le afecta tambien al suscritor y al lector de los periódicos; gracias á nosotros tiene un periódico bueno muy barato.

[...] Nuestros intereses están en que se sepa de una vez la verdad respecto de la tirada que tienen los periódicos de más circulacion, puesto que hasta ahora eso sirve de regulador para los precios que se nos hace pagar.

[...] Nosotros hemos preferido siempre para el anuncio La Correspondencia... ¿Por qué? Por una sola razón, la más elocuente: porque nos ha dado resultado [...]. Nosotros los anunciantes, nos hemos retraído de El Imparcial por la misma razón, es decir, porque hemos visto que el anuncio en El Imparcial no nos produce efectos. 
Es cuestión de libro de caja más que de lógica.

[...] Ustedes se han apoderado desde el primer golpe de ciertas clases que son el público del anuncio, El Imparcial, que lleva quince años de propaganda sin oposicion, es más leído en las clases impropiamente llamadas bajas, que, como más pobres, no pueden responder al anuncio como las otras.

[...] Nosotros sabemos, además, que la mayor tirada no es todo para el efecto del anuncio, nosotros queremos periódicos que se lean. ¿De qué nos sirven los periódicos que el público tiene costumbre de pagar, pero que no desdobla y que deja intactos en la mesa? Un solo número que tenga muchos lectores vale más que muchos números que no tengan lector. ¿Me explico?

Varios temas destacan en este comunicado; primero, la trascendencia que la publicidad tiene para la prensa y para el lector, pues gracias a aquélla es posible la baratura y la calidad. Planteamiento con el que Emile de Girardin concibió La Presse en 1836, lanzado a mitad del precio habitual de la época por la inserción de publicidad en sus planas. En segundo lugar, se aprecia cómo la tirada actuaba ya como regulador de los precios; se entiende que ésta fuera motivo de continuas fricciones. Fue también Girardin el que anticipó este criterio de facturación para las inserciones publicitarias. Pero además, se valora y distingue la importancia de la tirada frente a la audiencia. Los anunciantes conocían a finales del siglo XIX el valor publicitario de las distintas cabeceras, de las que les interesaba, precisamente, su audiencia.

Tercero, el reconocimiento del tema de la efectividad publicitaria medida en resultados crematísticos: los anuncios en según qué periódicos no producen efectos en "el libro de caja". Esta crítica provenía de la costumbre de editar numerosos ejemplares al objeto de regalarlos a los suscriptores de otros periódicos. Era una acción de promoción, pero también una forma artificial de incrementar la tirada, y los anunciantes lo sabían.

Por último, y en cuarto lugar, un elemento hoy vital en la planificación de una campaña publicitaria es el "público objetivo". El cuarto párrafo contiene una mención que, próxima al actual concepto de audiencia, se centra en el poder adquisitivo de los lectores, y que anticipa la relación de la audiencia (clase alta) con el posible consumidor. Los anunciantes se muestran reacios a gastar en un periódico leído por clases que no podían responder al anuncio, es decir, que no disponían de renta para gastar.

La Correspondencia de España, El Imparcial y El Liberal defendieron las inserciones publicitarias como el único medio que un periódico tenía de ser independiente; los tres asumieron su carácter de empresa mercantil; los tres tutelaron lo que la historia ha denominado "periodismo de empresa", y los tres rebasaron su tradicional, y hasta entonces único, sentido de medios de comunicación social 
326 Avisos, anuncios, reclamos y publicidad en España. Siglos XVIII y XIX

para comportarse como soportes publicitarios.

\subsection{El Gratis: diario de anuncios}

Tenemos constancia de una curiosa publicación que no hace sino abundar en la tesis de que la actividad anunciadora en nuestro país discurría en una línea similar a la de otros países europeos. Se trata de un peculiar periódico que se publicó en Madrid el 1 de agosto de 1842 llamado El Gratis porque distribuía gratuitamente sus primeros dos mil ejemplares. Aunque no superó el medio año de vida (cesó el 15 de enero de 1843), el contenido de su primer número es un inapreciable retrato de la situación anunciadora de la época.

Junto a la cabecera se explican las modalidades y precios de los anuncios, así como las tres ediciones del periódico: la primera, diaria para Madrid²; la segunda, semanal para provincias; y la tercera, de carteles, los jueves y domingos. Las dos primeras se distribuían gratis hasta el número de 2.000 ejemplares a establecimientos de gran concurrencia, pagando un real mensual para gasto de repartidores, lo que podríamos interpretar como antecedente de la prensa gratuita en España, ya que iría más allá de las formas indirectas de gratuidad que reducían el precio de venta con fórmulas como el envío (gratis) de ejemplares durante un tiempo a fin de promover la venta y suscripción o de luchar contra la competencia, los regalos a suscriptores o la inserción gratuita de anuncios (Edo, 2005: 6).

En la misma portada, y a continuación, se exponen diversos temas de índole publicitaria; sobresalen por su novedad los elogios a la publicidad, las críticas a las formas anunciadoras del momento y las comparaciones con la publicidad vigente en países como Gran Bretaña y Francia.

Respecto a lo primero, los editores de El Gratis declaran "emprender una nueva misión" como es la de investigar las ventajas de la publicidad, censurando el menosprecio que padece en España; precisamente, esta falta de interés es valorada como una de las razones del atraso de nuestra industria y comercio. La publicidad es, según sus editores, imprescindible para la prosperidad económica del país frente a la desatención a formas publicitarias que pudieran mejorar la de los primeros avisos — de líneas y casi ininteligibles — de un siglo atrás: "Siempre se encuentra lo mismo en nuestro viejo Diario de avisos, siempre la misma letanía de traspasos y huéspedes, de pérdidas y nodrizas, de jabón quita-manchas y ungüentos para los callos" (1-8-1842: 1). A mayor abundamiento, censuran las fuertes reticencias ante la publicidad en prensa; frente a ella, el ejemplo de Francia con el Diario de los debates, y de Inglaterra, con el Times, cuyas páginas aparecían abigarradas de anuncios de todas clases y dimensiones.

Una de las cuestiones más sorprendentes de esta declaración de intenciones

\footnotetext{
${ }^{2}$ Sin embargo, entre el $n^{\circ} 1$ (1 de agosto de 1842) y el $n^{\circ} 2$ (8 de agosto de 1842) transcurrió una semana.
} 
de los editores de El Gratis es la difusión de los anuncios; para ello proponen, al igual que en el extranjero, publicar ediciones exclusivamente destinadas a otras ciudades de España y al extranjero, sin que el precio de su inserción se incremente a tenor del número de diarios en que pudieran aparecer; así, por ejemplo, si un anunciante quería anunciarse en veinticinco poblaciones "á cuatro cuartos la línea, cuesta precisamente cien cuartos, mientras que la misma línea no costaría en el Gratis más que cuatro cuartos, haciéndola circular no solo por esas veinte y cinco poblaciones, sino por toda España: diferencia, 96 cuartos en línea, y publicidad inmediata é instantánea" (1-8-1842: 1).

Esta nueva entidad estaba obrando, salvando notables diferencias, como una central de medios, lo que se aprecia, sobre todo, cuando explica que los anuncios, a cuatro cuartos línea, podían insertarse a la vez en varias ediciones de provincias y del extranjero. Es ésta, básicamente, la función de una central de medios. La filosofía de este acuerdo y la que poseen hoy las centrales es similar, por lo que creemos que es posible considerar este modo de operar como un precedente de éstas (Pérez Ruiz, 2001: 104).

Otra novedad del periódico fue la concurrencia de dos medios - prensa y cartel- La tercera edición consistía en carteles con anuncios que se fijaban por todo Madrid de jueves a domingo "en diversos colores para llamar más la atención", explicitándose las ventajas de su tiempo de exposición. Además, y a petición, se daba gratis un cartel a todo aquel que lo solicitase para fijar en su puerta (1-8-1842: 2). Con esta acción, los editores del diario se mostraban conscientes del mayor alcance y penetración que podía lograrse con la actuación conjunta de dos medios publicitarios.

En lo relativo a la edición de Madrid, la estructura del diario consistía en dos secciones; la primera contenía cuatro apartados: 1) Agenda pública, con contenidos religiosos, espectáculos; 2) Noticias comerciales, bibliográficas y sociales; 3) Artículos sobre curiosidades instructivas y 4) Reclamos y artículos comunicados. La segunda incluía los anuncios, clasificados en quince grupos. En la primera parte, apartado 4, sobresale el nuevo uso dado a la palabra reclamo. Como decíamos al principio, los editores de El Gratis la tomaron prestada del francés por no existir una voz equivalente en castellano. El reclamo fue muy habitual en el primer tercio del siglo XX, consolidándose como forma publicitaria junto al pequeño anuncio y el anuncio propiamente dicho. Así lo testimonian los principales tratadistas del momento como Prat Gaballí (1917: 63-68) y Bori y Gardó (1928: 67):

1. El pequeño anuncio, en la sección de pequeños avisos, era una ampliación del texto informativo del periódico. Hoy equivale a los anuncios por palabras.

2. El anuncio propiamente dicho. Carecía de lugar fijo en el periódico, debido a que la distribución y rapidez de la numeración de planas se dejaban en 
328 Avisos, anuncios, reclamos y publicidad en España. Siglos XVIII y XIX

manos del impresor.

3. Reclamo o publicidad redaccional. Aunque las voces reclamo y anuncio se utilizaban frecuentemente como sinónimas, no lo eran, quedando la primera reservada para el anuncio disimulado, en forma de artículo, noticia, etc. (Prat Gaballí, 1917: 67). Publicidad velada, con apariencia de autoridad y revestida formalmente de rasgos periodísticos que disfrutaba de aceptación en algunos países. El reclamo tenía dos modalidades: la gacetilla y el artículo. La primera se intercalaba entre las noticias de una sección. El segundo se redactaba como si fuera una colaboración y podía ir firmado, o no, pero siempre con título, subtítulos, etc. (Bori y Gardó, 1928: 67-69). En nuestros días es ilegal esta clase de publicidad (La Ley 34/1988 General de Publicidad, artículo 11). En efecto, cualquier mensaje publicitario que adopte la forma y el estilo de la redacción periodística ha de ser destacado con los términos publicidad o publirreportaje.

Al igual que hiciera Nipho en 1758, la segunda parte de El Gratis distribuía los anuncios recibidos en quince apartados. De nuevo nos hallamos ante una tipología de anuncios, incrementada en cinco grupos respecto a la del editor aragonés: 1) Avisos oficiales; 2) Instrucción pública, sociedades, audiencias, colegios y profesores; 3) Industria, economía, agricultura; 4) Asociaciones, préstamos; 5) Ventas de fincas; 6) Ventas particulares; 7) Ventas del comercio; 8) Colocaciones; 9) Mensajerías, transportes, caminos, navegaciones; 10) Traspasos, alquileres, huéspedes; 11) Establecimientos públicos; 12) Pérdidas y hallazgos; 13) Avisos diversos; 14) Librería, música, estampas y 15) Diversiones públicas.

Se trata ahora de conjuntos más homogéneos y de títulos más precisos, resultado de la evolución económica y social; no en vano, entre una y otra clasificación distan ochenta años. Los sectores están más perfilados: Colocaciones, por ejemplo, ocupa aquí un solo epígrafe frente a los tres grupos del diario de Nipho (servicio doméstico, criados, nutrices). Asimismo, se constatan otros nuevos como el grupo noveno, equivalente al actual de Transportes y comunicaciones de Infoadex.

Tras la clasificación de anuncios se relacionan los precios de las diferentes formas anunciadoras, entre las que destacan los "anuncios sobresalientes", reservados a la última página. Se trata de una novedosa forma publicitaria, habitual en Francia y para la que los editores consideran importantes ventajas por su gran tamaño y por la inclusión de grabados y viñetas, esto es, comienza a apreciarse la imagen en la publicidad.

Otro hecho de gran trascendencia para la historia de la prensa y la publicidad es la constitución de una sociedad, de cinco años de duración, con un capital de 100.000 reales, divididos en veinte acciones de 5.000 reales que, a su vez, se dividen en décimos de 500 reales. Dicen los fundadores tener cubierto un número de acciones suficiente para la marcha de El Gratis durante seis meses al menos. La creación de esta sociedad en 1842 significa el primer testimonio 
de una empresa en España para la explotación de anuncios, cometido que hasta hoy se atribuía a la Sociedad General de Anuncios, fundada en 1881 por Adolfo Rodríguez Calzado. Es una referencia valiosa para la historia de la publicidad española porque confirma la existencia de vínculos comerciales modernos entre prensa y publicidad. Así mismo, la creación de una empresa orientada a tal fin prueba que la actividad publicitaria empezaba a rebasar el lejano hecho anunciador/avisador para precisar de organizaciones que ayudaran a los anunciantes en la comunicación de sus productos y servicios.

Sin embargo, El Gratis apenas se editó durante seis meses; este fracaso pone de manifiesto que no existió demanda, quizá porque los anunciantes no estaban dispuestos a pagar por un servicio que hasta la fecha había consistido en deslavazados, escuetos y tediosos anuncios de escasa eficacia, o bien por la falta de espíritu innovador de empresarios y comerciantes. La tranquilidad del momento histórico abunda en esta consideración, pero también el atraso de nuestra industria y comercio (los mismos editores lo manifiestan). Estas iniciativas muestran, eso sí, la existencia de individuos que conocían el auge de la publicidad en los países más industrializados, que creyeron en ella y que impulsaron proyectos para favorecer su uso y aplicación en España.

\section{CONCLUSIONES}

La relación de periódicos examinada ha resultado ser una fuente documental fértil en el hallazgo de formas publicitarias. Dado el período de estudio, la consulta de cabeceras de la época es imprescindible si se desea progresar en el conocimiento histórico de la primera publicidad en España en su sentido moderno. Por una parte, los diarios del siglo XVIII confirman la introducción de avisos, tal y como había empezado a suceder en países precursores como Gran Bretaña y Francia; por otra, las planas de los periódicos decimonónicos, sobre todo los de gran tirada, no sólo se llenan de anuncios y reclamos, sino que atesoran noticias, reflexiones y polémicas en torno a la empresa periodística y a la publicidad; aspectos que ninguna investigación sobre la publicidad de la época debería desatender.

En ambos siglos, estos anuncios son un jugoso retrato de la sociedad de la época, pero además contienen tipologías publicitarias novedosas: la primera, la de Nipho, en 1758, fue traslada cuatro años después por Tarazona a su periódico; la tercera, de quince grupos, data de 1842 y se publicó en El Gratis. Al relacionar estas clasificaciones con la actual de Infoadex se encuentran representados los siguientes sectores: Alimentación, Automoción, Bebidas, Construcción, Cultura, Enseñanza y medios de comunicación, Deportes y tiempo libre, Hogar, Objetos personales, Servicios públicos y privados, Textil y vestimenta Transportes y comunicaciones y Varios. De manera que es posible conocer qué actividades productivas fueron las primeras en interesarse por esta nueva forma de comunicación —la publicidad-, que el tiempo habría de consolidar.

De gran valor, por último, ha sido el hallazgo de una cabecera -El Gratis- 
330 Avisos, anuncios, reclamos y publicidad en España. Siglos XVIII y XIX

por varios motivos: para la prensa porque nos hallarnos ante lo que podría ser el primer modelo de diario cuasi gratuito y precedente, en consecuencia, de esta modalidad de prensa en España; para la publicidad, porque desde sus páginas se defiende y reflexiona sobre ella, lo que podría llegar a considerarse como un tratado publicitario (quizá el primero). Creemos que desarrollar líneas de investigación sobre las formas publicitarias en la prensa de estos siglos contribuiría a consolidar el conocimiento de los orígenes de la publicidad en España.

\section{REFERENCIAS BIBLIOGRÁFICAS}

ALTABELLA, J.: "La Correspondencia de España. Notas para una historia de la publicidad". IP: Información de la Publicidad, (Diciembre 1963), n 7, pp. 15-18.

-"La prensa aragonesa de ayer a hoy". IP: Información de la Publicidad, (Junio 1964), nº 10 , pp. 58-61.

AUBEYZÓN LLOPIS, J.: "Datos y documentos para la Historia de la Publicidad". En AA. VV. (¿1928?): Curso de Publicidad y Organización. Barcelona: Cultura, pp. 11-34.

BAUDRILLARD, J. (1974): La sociedad de consumo. Barcelona: Plaza y Janés.

BORI, R., y GARDÓ, J. (1928): Manual práctico de publicidad. Barcelona: Cultura.

BROTEL, J-F.: "Estadística de la prensa madrileña de 1858 a 1909, según el Registro de Contribución Industrial”. En TUÑÓN DE LARA, ELORZA y PÉREZ LEDESMA (eds.) (1975): Prensa y sociedad en España (1820-1936). Madrid: Edicusa, pp. 25-45.

CASTILLO, S. J.: "La prensa diaria de Madrid: notas para el análisis de las estadísticas del timbre (1873-1887)". En TUÑÓN DE LARA, ELORZA y PÉREZ LEDESMA (eds.) (1975): Prensa y sociedad en España (1820-1936). Madrid: Edicusa, pp. 149-198.

CHECA GODOY, A. (2007): Historia de la publicidad. La Coruña: Netbiblo.

-"La Historia de la comunicación y las nuevas tecnologías". En FELIU GARCÍA, E. (coord.) (2008): Comunicación, memoria, historia, modelos. Madrid: Edipo.

DUBOIS, J. et alter (1998): Diccionario de lingüística. Madrid: Alianza Editorial, pp. 440-441. EDO BOLÓS, C.: "El éxito de los gratuitos hace más visible la crisis de la prensa diaria de pago". Estudios sobre el mensaje periodístico, (2005), n 11, pp. 23-44.

FERNÁNDEZ POYATOS, M ${ }^{a}$ D.: "La publicidad de la salud en la prensa ilustrada del siglo XIX”. Questiones publicitarias, vol. I, (2011), n 16, pp. 103-119.

GALBRAITH, J. K. (1968): La sociedad de la opulencia. Barcelona: Ariel.

GUILLAMET, J.: "Diaris preinformatius. Sobre Diario Curioso i els orígens de Diario de 
Barcelona". Periodística: revista acadèmica, (2001), n 10, pp. 41-50.

GUTIÉRREZ GAMERO, E. (1925): Mis primeros ochenta años. Madrid: Aguilar.

MALALANA UREÑA, A.: "Fuentes de información para el análisis de la Publicidad. Las bases de datos publicitarias e Internet". Cuadernos de Documentación Multimedia, (2004), $\mathrm{n}^{\circ} 15$.

NIETO, A. (1984): La prensa gratuita. Eunsa: Pamplona.

PÉREZ RUIZ, M. Á. (2001): La publicidad en España. Anunciantes, agencias y medios. 1850-1950. Madrid: Fragua editorial.

PRAT GABALLÍ, P. (1917): Una nueva técnica: la publicidad científica. Lecciones explicadas en las Clases de Enseñanza Mercantil de dicha Corporación durante el Curso 1915-16. Barcelona: Imprenta de Henrich y C.a.

REAL ACADEMIA ESPAÑOLA (1726): Diccionario de la lengua castellana [...]. Compuesto por la Real Academia Española. Madrid: Imprenta de Francisco del Hierro.

-(1937): Diccionario de la lengua castellana [...]. Compuesto por la Real Academia Española. Madrid: Imprenta de la RAE, herederos de Francisco del Hierro.

-(1822): Diccionario de la lengua castellana por la Real Academia Española. Sexta edición. Suplemento. Madrid: Imprenta Nacional.

-(1899): Diccionario de la lengua castellana por la Real Academia Española. Madrid: Imprenta de los Sres. Hernando y compañía.

-(1925): Diccionario de la lengua española. Madrid: Calpe.

-(1933): Diccionario histórico de la Lengua Española. Tomo L-A. Madrid: Imprenta de Librería y Casa Editorial Hernando.

-(1970): Diccionario de la lengua española. Decimonovena edición. Suplemento. Madrid: Espasa-Calpe.

RUEDA, J. C: "Industrialización y empresas informativas en el Madrid del siglo XIX". Historia y Comunicación Social, (1999), $\mathrm{n}^{\circ}$ 4, pp. 341-359.

RUEDA, J. C. y BARBERO, S.: "Empresas financieras y publicidad comercial en el Madrid isabelino, 1861-1866". Semata, vol. 12, (2000), pp. 109-123.

SÁlZ, Ma D. (1990): Historia del periodismo en España. 1. Los orígenes. El siglo XVIII. Madrid: Alianza Universidad Textos.

SEOANE, Ma C. (1992): Historia del periodismo en España. 2. El siglo XIX. Madrid: Alianza 
332 Avisos, anuncios, reclamos y publicidad en España. Siglos XVIII y XIX

Universidad Textos.

Breve semblanza de los autores

$\mathbf{M}^{\mathrm{a}}$ Dolores Fernández Poyatos es Doctora por la Universidad de Alicante, con la tesis: "Origen y evolución de la actividad publicitaria en España. 1880-1936". Profesora del Dpto. de Comunicación y Psicología social (Universidad Alicante) y autora de diversas publicaciones, desarrolla su actividad docente e investigadora en el área de la Historia de la publicidad, la Comunicación turística y la Estrategia publicitaria.

Emilio Feliu García es profesor titular de universidad de comunicación audiovisual y publicidad; director del grupo de estudios sobre publicidad institucional política y social (Gepips). Su actividad docente e investigación se ha centrado fundamentalmente en Lenguaje publicitario y en la publicidad como forma de comunicación social. Director de varias tesis doctorales.

(Recibido el 13-09-2011; aceptado el 10-11-2011) 